\title{
Analysis of plasma proteins using 2D gels and novel fluorescent probes: in search of blood based biomarkers for Alzheimer's disease
}

\author{
Scott B. Laffoon 1,2,3, James D. Doecke ${ }^{4}$, Anne M. Roberts ${ }^{5,6}$, Jennifer A. Vance ${ }^{7}$, Benjamin D. Reeves ${ }^{2}$, \\ Kelly K. Pertile ${ }^{1}$, Rebecca L. Rumble ${ }^{1}$, Chris J. Fowler ${ }^{1}$, Brett Trounson ${ }^{1}$, David Ames ${ }^{1}$, Ralph Martins ${ }^{3,8,9}$, \\ Ashley I. Bush ${ }^{1,3}$, Colin L. Masters ${ }^{1,3}$, Paul A. Grieco ${ }^{2}$, Edward A. Dratz ${ }^{2}$ and Blaine R. Roberts ${ }^{5,6^{*}}$ (D)
}

\begin{abstract}
Background: The Australian Imaging and Biomarker Lifestyle (AIBL) study of aging is designed to aid the discovery of biomarkers. The current study aimed to discover differentially expressed plasma proteins that could yield a bloodbased screening tool for Alzheimer's disease.

Methods: The concentration of proteins in plasma covers a vast range of 12 orders of magnitude. Therefore, to search for medium to low abundant biomarkers and elucidate mechanisms of AD, we immuno-depleted the most abundant plasma proteins and pre-fractionated the remaining proteins by HPLC, prior to two-dimensional gel electrophoresis. The relative levels of approximately 3400 protein species resolved on the 2D gels were compared using in-gel differential analysis with spectrally resolved fluorescent protein detection dyes (Zdyes ${ }^{\mathrm{TM}}$ ). Here we report on analysis of pooled plasma samples from an initial screen of a sex-matched cohort of 72 probable AD patients and 72 healthy controls from the baseline time point of AIBL.
\end{abstract}

Results: We report significant changes in variants of apolipoprotein E, haptoglobin, a1 anti-trypsin, inter-a trypsin inhibitor, histidine-rich glycoprotein, and a protein of unknown identity. a1 anti-trypsin and a1 anti-chymotrypsin demonstrated plasma concentrations that were dependent on APOE $\varepsilon 4$ allele dose. Our analysis also identified an association with the level of Vitamin D binding protein fragments and complement factor I with sex. We then conducted a preliminary validation study, on unique individual samples compared to the discovery cohort, using a targeted LC-MS/MS assay on a subset of discovered biomarkers. We found that targets that displayed a high degree of isoform specific changes in the 2D gels were not changed in the targeted MS assay which reports on the total level of the biomarker.

Conclusions: This demonstrates that further development of mass spectrometry assays is needed to capture the isoform complexity that exists in theses biological samples. However, this study indicates that a peripheral protein signature has potential to aid in the characterization of AD.

Keywords: Proteomics, 2D-PAGE, Alzheimer's disease, Biomarkers, Plasma, APOE, Zdye, Blood

*Correspondence: blaine.roberts@emory.edu

${ }^{6}$ Department of Neurology, Emory School of Medicine, 4001 Rollins Research Building, Atlanta, GA 30322, USA

Full list of author information is available at the end of the article

\section{Introduction}

Alzheimer's disease (AD) is the most common cause of dementia, accounting for $60-80 \%$ of cases [1]. It is estimated that there are over 40 million people suffering from $\mathrm{AD}$ dementia, with the number expected to rise to original author(s) and the source, provide a link to the Creative Commons licence, and indicate if changes were made. The images or other third party material in this article are included in the article's Creative Commons licence, unless indicated otherwise in a credit line to the material. If material is not included in the article's Creative Commons licence and your intended use is not permitted by statutory regulation or exceeds the permitted use, you will need to obtain permission directly from the copyright holder. To view a copy of this licence, visit http://creativecommons.org/licenses/by/4.0/. The Creative Commons Public Domain Dedication waiver (http://creativeco mmons.org/publicdomain/zero/1.0/) applies to the data made available in this article, unless otherwise stated in a credit line to the data. 
over 100 million by the year 2050 [1]. More than $75 \%$ of those afflicted with dementia remain undiagnosed [2]. While a small portion of AD cases are familial, 95\% of AD cases are late onset or "sporadic", being of unknown and possibly heterogeneous etiology [3].

Currently, the diagnosis of $\mathrm{AD}$ is made by clinical assessments of cognitive impairment, with the exclusion of diagnosis for other dementias. With the addition of brain imaging techniques, the accuracy of diagnosis is approximately $90 \%$ [4]. The gold standard for the pre-mortem diagnosis of $\mathrm{AD}$ involves positron emission tomography (PET) imaging of amyloid load in the brain [5]. Due to the expense, low availability, and the technically challenging nature of PET imaging it is not suitable for population screening and there is a large research effort to develop peripheral screening tools that can be used to detect those at risk of developing AD. Investigations of cerebrospinal fluid (CSF) biomarkers are proving to be effective for early detection of $\mathrm{AD}$ risk $[6,7]$. However, the collection of CSF is not a widespread practice, as it requires an invasive lumbar puncture, as compared with much less-invasive blood tests. This situation has led to an intensive search for blood based biomarkers that may reflect changes in $\mathrm{AD}$ that are systemic, or due to either the disruption of the blood-brain barrier (BBB) $[8,9]$ or the trafficking of proteins between the brain and blood [10]. While AD is conceptually a brain disease, there is evidence of altered protein expression in the periphery. This has been shown in several avenues of research, including AD related morphological, chemical and proteomic changes in red-blood cells [11-14], alterations of motility in white blood cells and changes in membrane fluidity in leukocytes [15-17], as well as reports of plasma biomarker panels [18-24]. Previous proteomics studies have detected significant changes in proteins found in plasma, serum and CSF in AD. However, none of these studies have yielded accurate, specific and reproducible diagnostic markers for AD [25-28]. This remains a significant challenge in the field, but there are indications that a blood-biomarker is possible as indicated by reports measuring the amyloid beta $40 / 42$ ratio, tau [29-33], p-tau [34].

Global discovery investigations of CSF and plasma proteins face an imposing dynamic range of analyte concentrations, spanning approximately 10 orders of magnitude $[35,36]$, whereas the various platforms for proteomic analysis of intact proteins are limited to the most abundant 3-5 orders of magnitude. With the immense heterogeneity of the immunoglobulins, plasma comprises many tens of thousands of protein species, of which approximately $50 \%$ by weight is serum albumin [37] and $92 \%$ of the plasma protein is composed of 14 of the most abundant proteins [38]. We used immuno-depletion to remove the 14 most abundant proteins from plasma. We then employed reverse phase high-pressure liquid chromatography (RP-HPLC) to provide further fractionation of less abundant species into simpler subsets of proteins. Proteins were subsequently measured with two-dimensional gel electrophoresis (2DGE). The advantage that 2DGE provides as a proteomic platform is its ability to detect changes in a very wide range of post translationally modified protein isoforms. We also employed a pooling strategy to incorporate a larger population in the study to reduce effects of individual variability and to emphasize changes that are related to disease [39, 40]. Using recently developed Zdyes [41, 42] for covalent labeling and differential in-gel comparison of $\mathrm{AD}$ and control plasma proteins, we conducted a proteomic screen of protein isoforms in samples obtained from the Australian imaging and biomarker lifestyle study of ageing (AIBL). We have confirmed several previously observed findings [23, 24] and report additional plasma protein signatures of $\mathrm{AD}$ that vary with APOE $\varepsilon 4$ gene dose and sex. Finally, we attempt to validate the discovered targets in individuals using a mass spectrometry-based platform.

\section{Methods and materials Diagnosis of subjects}

The Australian Imaging and Biomarker, Lifestyle (AIBL) study is a dual-site, longitudinal cohort study that integrates neuroimaging, biomarker, neuropsychometric and lifestyle [43]. The cohort was divided into two groups; cognitively healthy individuals (healthy controls, $\mathrm{HC}$ ), and participants diagnosed with $\mathrm{AD}$ as defined by NINCDS-ADRDA criteria [44] and majority were confirmed by amyloid PET. APOE genotypes were determined as previously described using PCR (Hixson and Vernier 1990)[45]. AIBL participant recruitment, cohort design and clinical assessments were previously described [43] and included comprehensive cognitive exam and amyloid PET imaging. Due to constraints in sample throughput we pooled samples from each diagnostic category, the demographic and biometric compositions of these pooled groups of samples are shown in Table 1. The MMSE score for individuals described as controls was greater than 28 and for AD cases the MMSE was less than 24 . We also used the pooling strategy to obtain a measure of the average change in disease. Further, we generated $n=6$ pooled groups from Control and $\mathrm{AD}$ to estimate the variance and significance of discovered biomarkers. Pools for each group were generated from $n=12$ individuals from each category e.g. 12 females with $\mathrm{AD}$ diagnosis were pooled together and in total we analysed three pools generated from 36 unique samples for $\mathrm{AD}$ females and similarly for $\mathrm{AD}$ males, and Control males and females. The demographics and 
Table 1 Demographic data for each group of pooled plasma ( $n=12$ individuals per pool, three groups per condition). The $p$-value was calculated with a two-tailed Student's t-test between All AD and All controls only

\begin{tabular}{llllllll}
\hline Parameter & Female AD & Male AD & Female Controls & Male Controls & All AD & All Controls & $P$-value \\
\hline Age in years & $82.2(1.2)$ & $77.0(1.8)$ & $69.1(1.5)$ & $70.5(4.7)$ & $79.6(3.1)$ & $69.8(3.2)$ \\
\% APOE \&4 & $37.5(4.2)$ & $43.1(16.8)$ & $19.4(2.4)$ & $6.9(6.4)$ & $40.3(11.4)$ & $13.2(8.1)$ & 0.0001 \\
$\mathrm{BMI}\left(\mathrm{kg} / \mathrm{mg}^{2}\right)^{\mathrm{a}}$ & $25.2(1.2)$ & $24.6(1.7)$ & $27.2(1.7)$ & $25.9(0.3)$ & $24.9(1.4)$ & $26.5(1.3)$ & 0.0001 \\
$\mathrm{n}$ & 36 & 36 & 36 & 36 & 72 & 72 & 72 \\
\hline
\end{tabular}

a BMI values from 54/72 AD subjects, 60/72 control subjects. Samples are from the baseline timepoint of the ABIL study

biometric composition of the samples used for the validation of the markers discovered in the pooled samples are provided in Table 3. Ethical approval for this study was provided by The University of Melbourne Human Research Ethics Committee.

\section{Plasma collection}

Plasma was isolated from $15 \mathrm{~mL}$ of whole blood collected in two Sarstedt s-monovette ethylenediaminetetraacetic acid (EDTA) K3E (01.1605.008) $7.5 \mathrm{~mL}$ tubes with prostaglandin E1 (PGE1) (Sapphire Biosciences, $33.3 \mathrm{ng} / \mathrm{mL}$ ) pre-added to the tube (stored at $4{ }^{\circ} \mathrm{C}$ prior to use). After whole blood was collected from overnight fasted participants by venipuncture it was inverted several times and incubated on a laboratory orbital shaker for approximately $15 \mathrm{~min}$ at room temperature prior to plasma preparation. The whole blood was then combined into $15 \mathrm{~mL}$ polypropylene tubes and spun at $200 \mathrm{xg}$ at $20^{\circ} \mathrm{C}$ for $10 \mathrm{~min}$ with no brake. Supernatant (platelet rich plasma) was carefully transferred to a fresh $15 \mathrm{~mL}$ tube, leaving a $5 \mathrm{~mm}$ margin at the interface to ensure the buffy coat was not disturbed. The platelet rich plasma was spun at $800 \mathrm{~g}$ at $20^{\circ} \mathrm{C}$ for $15 \mathrm{~min}$ with the brake on. The platelet depleted plasma was then aliquoted into $1 \mathrm{~mL}$ Nunc cryobank polypropylene tubes (Thermo Scientific, USA) in $0.25 \mathrm{~mL}$ aliquots and transferred immediately to a rack on dry ice and transferred to liquid nitrogen vapor tanks $\left(-178^{\circ} \mathrm{C}\right)$ until required for the assays approximately 4 years after collection.

\section{Immuno-depletion and fractionation}

The EDTA plasma from 12 individuals, selected to be pooled together based on sex and disease status (Fig. 1), were thawed on ice for $1 \mathrm{~h}$. The plasma was centrifuged at $16,500 \mathrm{x} \mathrm{g}$ for $2 \mathrm{~min}$ and $50 \mu \mathrm{l}$ from each individual was mixed together to generate the final pooled samples. Three independent pools of EDTA plasma were prepared from 12 subjects from each of male $A D$ (mAD), female AD (fAD), male healthy control $(\mathrm{mHC}$ ) and female healthy control (fHC) groups. Forty five microliters of the pooled plasma samples were immuno-depleted, using a multiple affinity removal system (MARS) 14 column according to manufacturers' instructions (MARS-14, $4.6 \times 100 \mathrm{~mm}$, Agilent), as described in the supplementary material. Breifly, the flow-through contianing low abundance proteins were collected in $15 \mathrm{~mL}$ conical vials containing $0.82 \mathrm{~g}$ urea (SigmaUltra) and $23 \mu \mathrm{l}$ glacial acetic acid (EMD Chemicals), for a final concentration of $6 \mathrm{M}$ urea and $1 \%$ acetic acid. After complete mixing, the low abundant protein fractions were frozen and stored at $-80^{\circ} \mathrm{C}$ until reverse-phase (RP) fractionation. The low abundant material was further fractionated into six subfractions, using a C18 column (Agilent high-recovery macro-porous $4.6 \mathrm{~mm} \times 50 \mathrm{~mm}$ ) operated at $80^{\circ} \mathrm{C}$ (see supplemental material for details). Reverse phase fractions were lyophilized and then re-suspended for labelling, with two spectrally resolved fluorescent dyes (Zdye LLC, green emitting BDR-I-227 and blue emitting JAVI-187) [41, 42]. Both fluorescently labelled samples were mixed and first resolved by isoelectric focusing (IEF) on 24cm pH3-11 Immobiline ${ }^{\mathrm{TM}}$ Drystrips (GE Healthcare) followed by electrophoresis on 11\% SDS-PAGE gels in the second dimension (detailed methods are in the Supplemental materials). Gels were scanned for fluorescence, using a Typhoon ${ }^{\mathrm{TM}}$ Trio scanner (GE Healthcare), and false-color images were produced with ImageQuant software (GE Healthcare). Gel image files were imported into Progenesis SameSpots software (Nonlinear Dynamics) for processing, alignment and differential analysis of the relative amounts of protein species in AD and control pools, after normalizing spot volume intensities by the total spot volume intensity in each image. To control for any bias induced by the individual fluorescent dyes we reversed the fluorescent dye used on half of the samples within each clinical group.

Spot volumes were considered significantly changed if there was greater than a 1.3-fold change between groups and a $p<0.05$ with a false discovery rate of 0.05 , calculated as described in Storey et al. [46], when comparing the six pools $(N=12$ per pool) of AD subjects with six pools of healthy controls (HC). Additionally, protein spot intensities were compared within male and female pools between $\mathrm{AD}$ and $\mathrm{HC}$ groups (three pools each for each sex). When comparing differences between the sexes, 


\section{Experimental Work Flow}

1. Pool EDTA Plasma
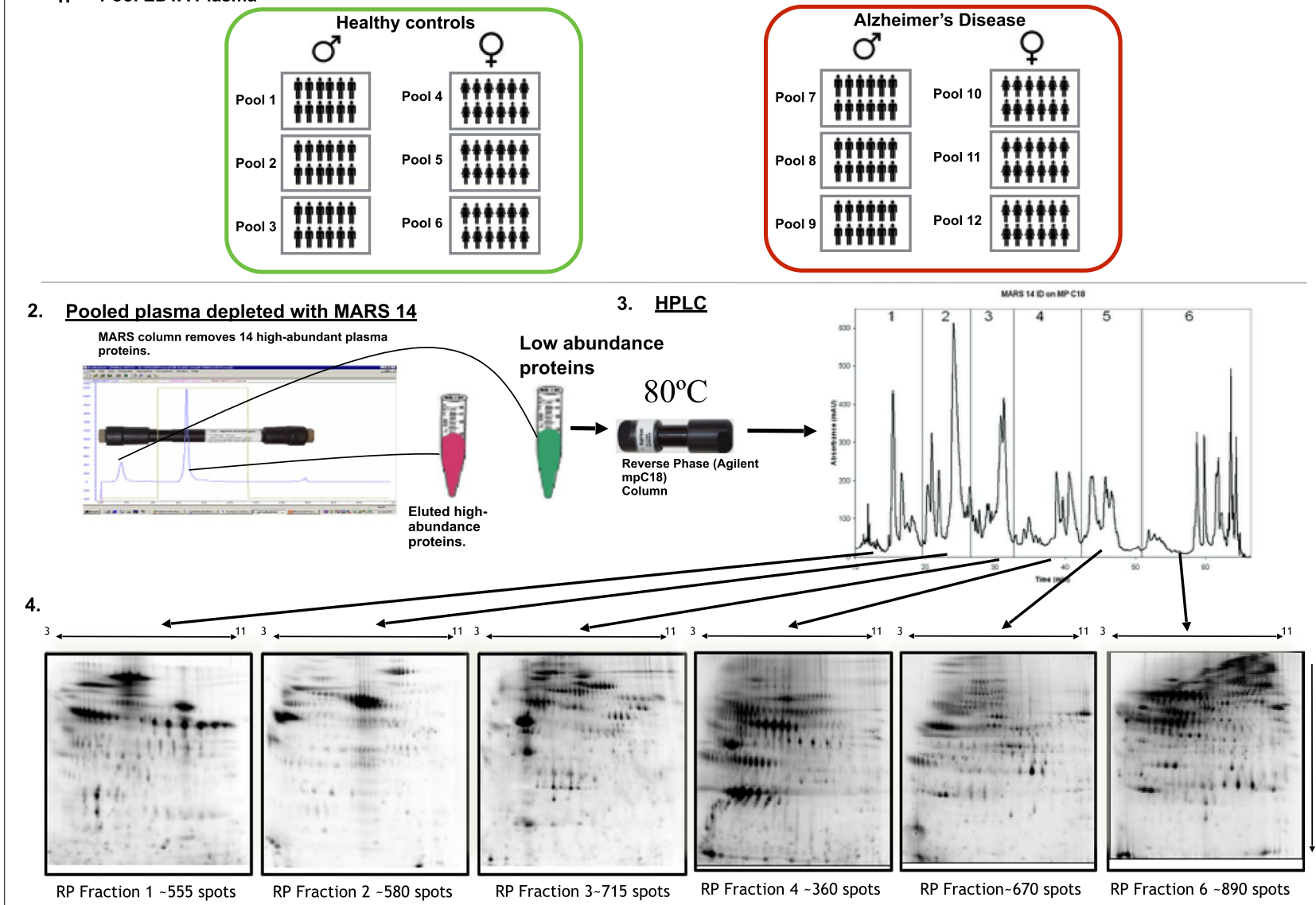

WNes 14 o in

Fig. 1 Study design and experimental workflow. (1) Shows how the control and Alzheimer's disease plasma was pooled into sex specific and disease specific groups. Each pooled group was generated from 12 individuals. (2) The pooled plasma was then depleted of the 14 most abundant proteins using the multiple affinity removal system (MARS14, Agilent Tech.). The low abundance proteins were further fractionated using reverse phase chromatography (3) to generate 6 fractions (4) for 2D differential gel electrophoresis of proteins labeled with Zdyes ${ }^{\mathrm{TM}}$ (4)

a cut-off of greater than 1.7 -fold change in protein levels was applied. Spearman's rank correlation and linear regression was used to assess the relationship between the number of APOE alleles and ApoE protein quantity.

\section{Identification of proteins-of-interest}

To identify changing protein variants, spots-of-interest were excised manually from analytical or preparative gels of fractionated proteins, for in-gel digestion with proteomics grade porcine trypsin (Sigma-Aldrich, Castle Hill, Australia), following previously published methods for in-gel digestion [47]. Mass spectrometry data (obtained as described in the supplementary material) were used to search the Swiss-Prot Homo sapiens database, using MASCOT version 2.4.1 (Matrix Science). Fixed modification of carbamidomethylation of cysteine, and variable modifications including oxidation of methionine, deamidation of asparagine and glutamine, and a single missed cleavage were allowed for the protein searches, using $2+$ and $3+$ peptide charge states.

\section{Selected reaction monitoring QQQ mass spectrometry}

The individual samples used in the quantitative mass spectrometry assay were unique compared to the samples utilized for the discovery section. The demographic details for this cohort are described in Table 3. Heavy isotopically labelled peptides were obtained as part of the BAK76 protein target kit from MRM-Proteomics (BAK76-kit, Canada). Samples were processed using the manufacturer's protocol (additional details in supplemental materials). Liquid chromatography mass spectrometry was conducted on with a 1290 UHPLC coupled to a 6495 QQQ mass spectrometer (Agilent Technologies).

Statistical analyses were conducted using: Progenesis QI (Waters, UK) for the 2D gel data; GraphPad Prism 
v 8.0 for Mac OS X (GraphPad Software, USA) for the ROC; t-test analysis: One-way ANOVA with Sidak correction of multiple comparisons and Chi-squared test. A $p$-value $<0.05$ was considered significant.

\section{Results}

Demographic details are listed in Table 1. The AD cohort was significantly older by 9.8 years (AD group $79.6 \pm 3.1$ years, $\mathrm{HC}$ group $69.8 \pm 3.2$ years, $p=0.0001$ ) and the $A D$ population was significantly enriched in the APOE $\varepsilon 4$ allele ( $40 \%$, AD; $13 \%, \mathrm{HC} ; p=0.0001)$ as anticipated [48]. Body mass index (BMI) data were available for $54 / 72 \mathrm{AD}$ subjects and $60 / 72 \mathrm{HC}$ subjects. The available data showed a trend $(p=0.06)$ of somewhat lower BMI in AD pools $\left(24.9 \pm 1.4 \mathrm{~kg} / \mathrm{m}^{2}\right)$ than HC pools $(26.5 \pm 1.1 \mathrm{~kg} /$ $\mathrm{m}^{2}$ ). All of the controls had an amyloid PET scan confirming the lack of significant brain amyloid accumulation and approximately half of 56/72 of the AD cases had a corresponding PET, which confirmed the AD diagnosis. An extensive analysis of the PET data collected on this cohort can be found in Pike et al. [49].

\section{Discovery 2D gel investigation of human plasma}

The immuno-depletion and RP-HPLC fractionation strategy produced six fractions (F1-6) of proteins for comparison by 2DGE (Fig. 1). Representative analytical gel images of each of the six RP fractions are shown in Fig. 2. Approximately 3400 unique protein species were analyzed by this method after reducing the total spot count by $10 \%$, to correct for proteins that were estimated to have eluted in more than one fraction. The inclusion of RP-HPLC fractionation resulted in a roughly linear six-fold increase in the number of protein spots measured. The increase was attributed to resolution of proteins that co-migrate on 2DGE, but have different hydrophobic characters and were separated by RP-HPLC. In addition, RPHPLC enriches proteins, allowing lower abundance species to appear with stronger fluorescent signals on the $2 \mathrm{D}$ gels.

Spots that met the inclusion criteria for significant differences in their fluorescent intensities $(>1.3$ fold, adjusted $p$-value $<0.05$ ), are indicated by the arrows in Fig. 2 and are listed in Table 2. Isoform variants, subunits or cleavage products of eight proteins that discriminated $\mathrm{AD}$ from control, according to the inclusion criteria, were identified: zinc $\alpha 2$-glycoprotein (ZAG), histidine-rich glycoprotein (HRG) fragment, haptoglobin (Hpt), vitamin D binding protein (VDBP), complement factor I (CFI), inter- $\alpha$ trypsin inhibitor (ITHI), $\alpha-1$ anti-trypsin ( $\alpha 1 \mathrm{AT}$ ) and apolipoprotein E (ApoE). One significant spot in fraction \#1 (F1) was

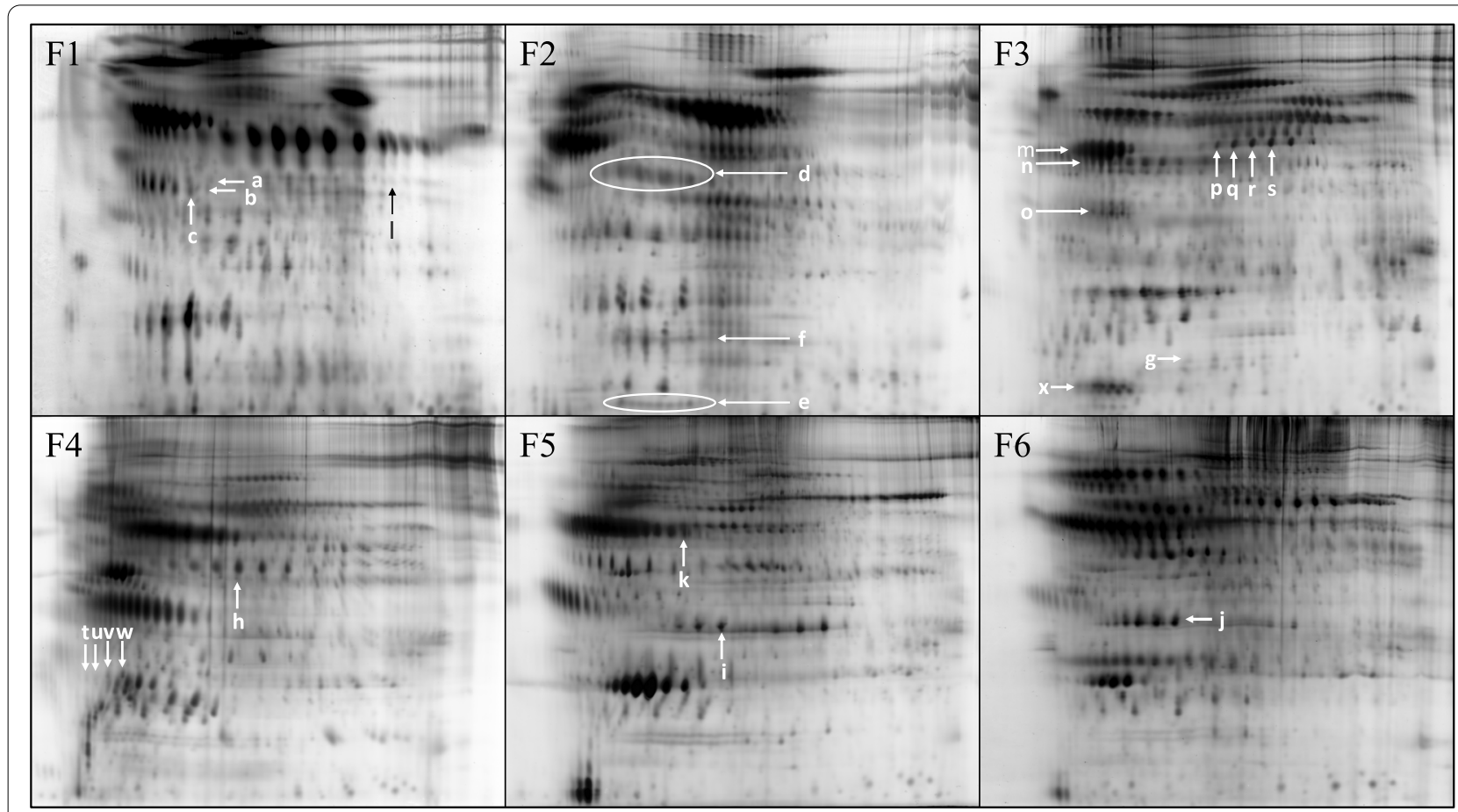

Fig. 2 Representative 2D gel images of proteins from the six-reverse phase HPLC fractions (F1-F6). The proteins were labeled with Zdyes ${ }^{\mathrm{TM}}$ but are displayed here on grey scale as it provides a better display allowing the lower abundant proteins to be visible. The arrows indicate the protein spots with abundance changes in AD pools compared to HC, as discussed in the Results and Discussion sections and illustrated in Figs. 3 and 5 


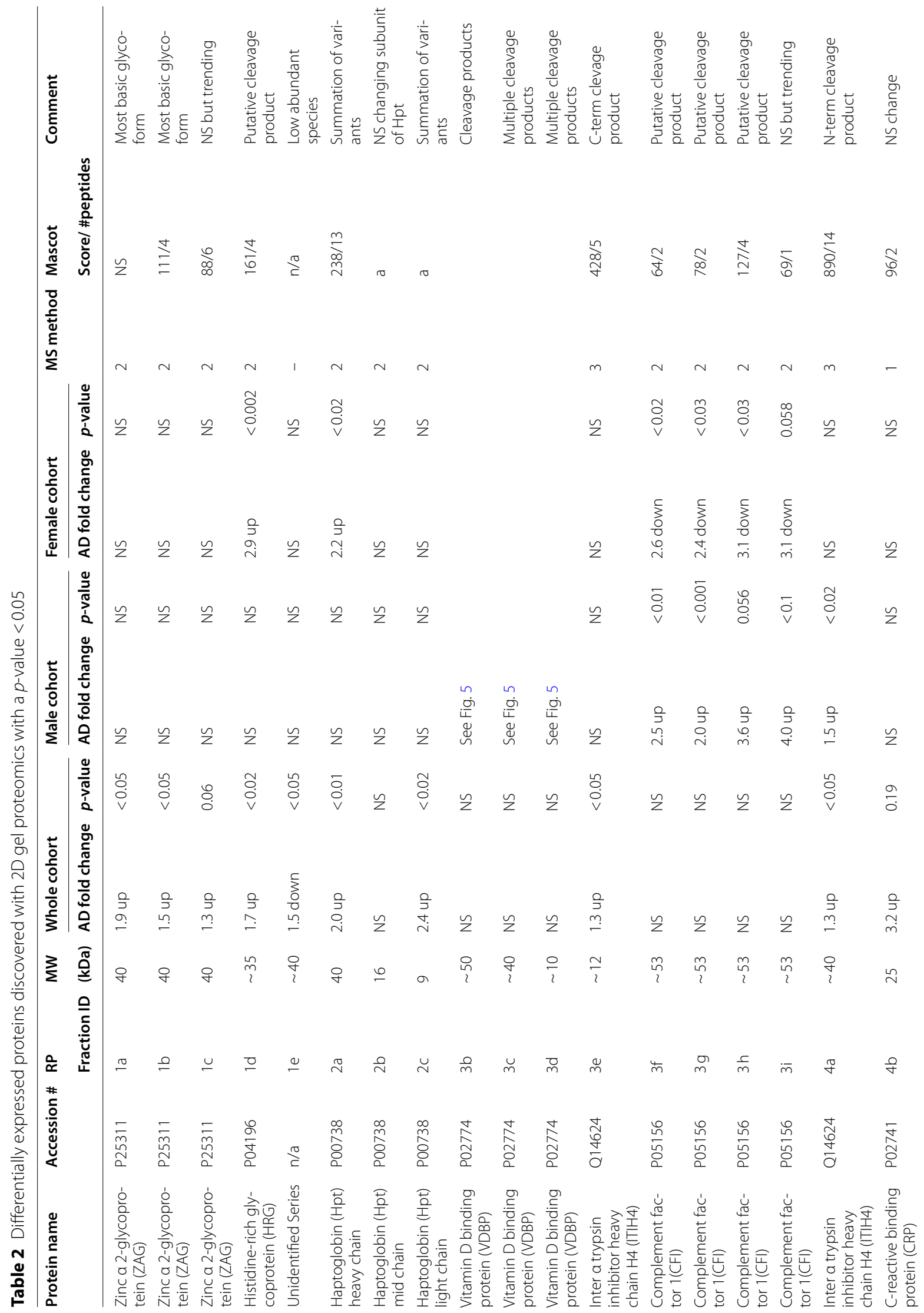




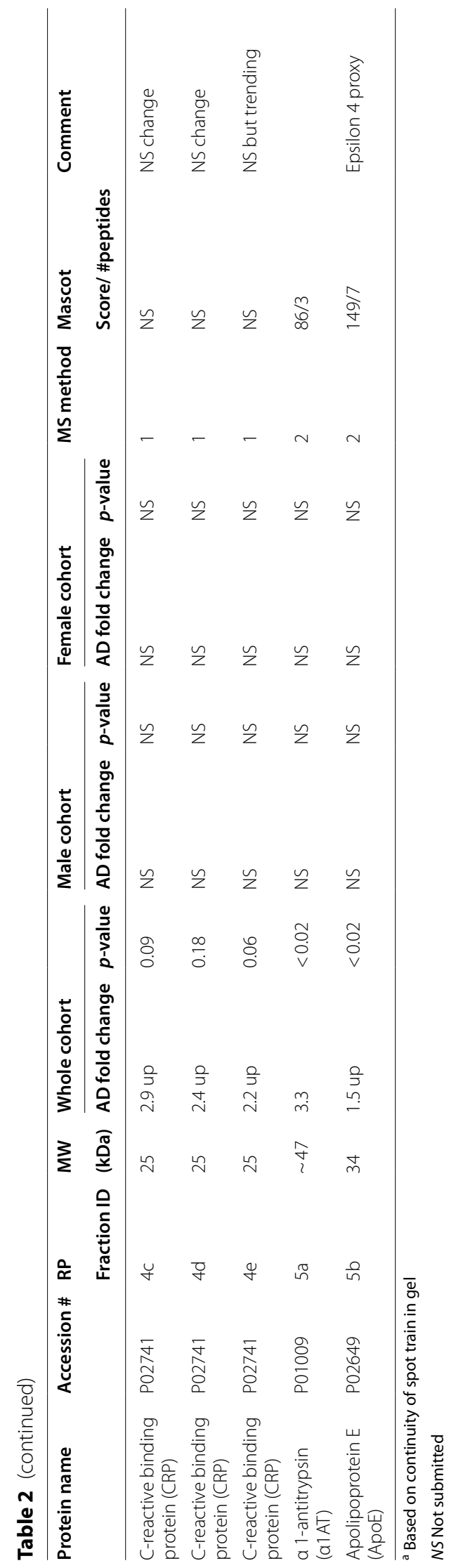


unidentified. Features of proteins that showed significant abundance changes are as follows:

\section{Zinc a 2-glycoprotein}

Two putative glycoforms of zinc $\alpha$ 2-glycoprotein (ZAG, Fig. 2 fraction 1 , arrows $a$ and $b$ ) showed significant increase in abundance in the AD pools (1.9-fold, $p<0.05$ and 1.5-fold, $p<0.05$ respectively, Table 2). An adjacent isoform (Fig. 2 fraction 1, arrow c) also showed a trend towards being increased in AD pools although it did not quite meet statistical significance (1.3-fold, $p=0.06)$.

\section{Haptoglobin}

Haptoglobin (Hpt) is an abundant, acute phase response (APR) polymeric glycoprotein that is synthesized in the liver and is composed of varied combinations of four disulfide linked chains (two $\alpha^{1}$ chains of $\sim 8.9 \mathrm{kDa}$ that differ by a single amino-acid substitution, $\alpha^{2}$ chain $\sim 16 \mathrm{kDa}$, and $\beta$ chain $\sim 45 \mathrm{kDa}$ ). Normal human populations commonly possess quaternary structural variations and heterogeneous stoichiometry of disulfide-linked $\mathrm{Hpt}$ chains [50], potentially yielding proteins composed of identical chains with differing pIs. In the current study the disulfide bridges were intact during isoelectric focusing then reduced before the SDS-PAGE dimension. This allowed the disulfide linked subunits of haptoglobin complexes to migrate at the same $\mathrm{pI}$ but resolve in the molecular weight dimension (Figs. 2 and 3). To avoid issues arising from mis-matching of heterogeneously focused spots in the comparison between pools, we quantified each of the Hpt spot-trains at $8.9 \mathrm{kDa}, 16 \mathrm{kDa}$ and $45 \mathrm{kDa}$ (Fig. 2 fraction 2, arrows $\mathrm{d}$, e, and $\mathrm{f}$ respectively) as the summed value of the respective constituent isoforms. Two haptoglobin (Hpt) chains ( $\beta$ chain $\sim 45 \mathrm{kDa}$ - Fig. 2 fraction 2 , arrow $\mathrm{d}$ and $\alpha^{1}$ chain $\sim 8.9 \mathrm{kDa}$ - Fig. 2 fraction 2 reverse phase fraction, arrow e) were significantly higher in AD pools (2.0-fold, $p<0.01$ and 2.4-fold, $p<0.02$ respectively, Table 2 ). No significant difference was found in Hpt $\alpha^{2}$ chain (Fig. 2 fraction 2, arrow f). False-color image overlays of the fraction 2 gels, qualitatively representing changes in Hpt species, are shown in Fig. 3, where the ovals in the upper right image indicate the three different subunit spot trains.

\section{Inter-a trypsin inhibitor}

Two cleavage products of inter- $\alpha$ trypsin inhibitor (ITIH) heavy chain were significantly higher in AD pools. A $12-15 \mathrm{kDa}$ C-terminal cleavage product (Fig. 2 fraction 3, arrow g) and an approximately $40 \mathrm{kDa} \mathrm{N}$-terminal cleavage product (Fig. 2 fraction 4 , arrow h) were both increased 1.3 fold in $\mathrm{AD}$ pools $(p<0.05$ and $p<0.02$ respectively, Table 2).

\section{Apolipoprotein E}

The most chemically basic protein spot of the apolipoprotein $\mathrm{E}$ (apoE) spot train (Fig. 2 fraction 5 , arrow i) was significantly higher in the AD pools ( 1.5 fold, $p<0.02$, Table 2). The $34 \mathrm{kDa}$ ApoE spot train results from the superposition of the protein products of the APOE $\varepsilon 2$, $\varepsilon 3$ and $\varepsilon 4$ alleles carried by the individuals contributing to the pools. Each of the alleles produces three clearly visible protein spot clusters. The clusters are likely due to heterogeneous deamidations and glycosylations [51]. The substitution of an arginine for a cysteine in apoE $\varepsilon 4$ $(\mathrm{C} 112 \mathrm{R})$, results in a basic rightward shift of its isoelectric point $(\mathrm{pI})$ toward the cathode relative to the apoE $\varepsilon 3$ position. Additionally, plasma proteins are subject to non-enzymatic deamidation in vivo, a process that adds negative charges [52], creating features of the horizontal spot trains by shifting protein species toward the anode, leftward on gels. The partially overlapping superposition of apoE $\varepsilon 3$ with $\varepsilon 4$ variants appeared as four clusters of spots in most of the pooled samples, with the most chemically basic cluster comprising only apoE $\varepsilon 4$ variants. Therefore, the most basic cluster of apoE spots provides a protein isoform proxy for the relative amounts of APOE $\varepsilon 4$ allele within the pools. Figure $4 \mathrm{~A}$ shows strong Pearson correlation $\left(R^{2}=0.82, p<0.0001\right)$ of the normalized spot intensity of the most basic apoE " $\varepsilon 4$ proxy" variant, with the averaged gene dosage of the APOE $\varepsilon 4$ allele in the pools of this study.

Fraction 6 gels exhibited a series (Fig. 2 fraction 6, arrow j) comprising six to seven variants of the same apparent molecular weight $(\sim 35 \mathrm{kDa})$ as the fraction 5 apoE series. However, none of the fraction 6 apoE variants significantly correlated with APOE genotype.

\section{a-1 anti-trypsin}

A circulating species of $\alpha-1$ anti-trypsin $(\alpha 1 \mathrm{AT})$ that was not bound by the immuno-depletion column (Fig. 2 fraction 5 , arrow $\mathrm{k}$ ) was significantly higher in $\mathrm{AD}$ pools (3.3 fold, $p<0.02$, Table 2 ). The $\alpha 1 \mathrm{AT}$ variant also closely correlated in regression analysis with the $\varepsilon 4$ proxy spot volumes (Fig. $4 \mathrm{~B}, R^{2}=0.83, P<0.0001$ ). The $\alpha 1 \mathrm{AT}$ variant that correlated with the $\varepsilon 4$ proxy spot is shown in Fig. 4D, where the $i$ panel has low $\varepsilon 4$ proxy and the $i i$ panel has high $\varepsilon 4$ proxy. The relationship of these spots is qualitatively represented in the false-color image overlay in Fig. 4C, indicated by white arrows. An unidentified protein spot (Fig. 2 fraction 1, arrow l) was significantly lower (1.5-fold, $p<0.05$, Table 2$)$ in AD pools.

\section{Sex specific differences}

Vitamin D binding protein (VDBP) cleavage product isoforms, (Fig. 1 fraction 3, arrows $\mathrm{n}, \mathrm{o}, \mathrm{x}$ and Fig. 5, 


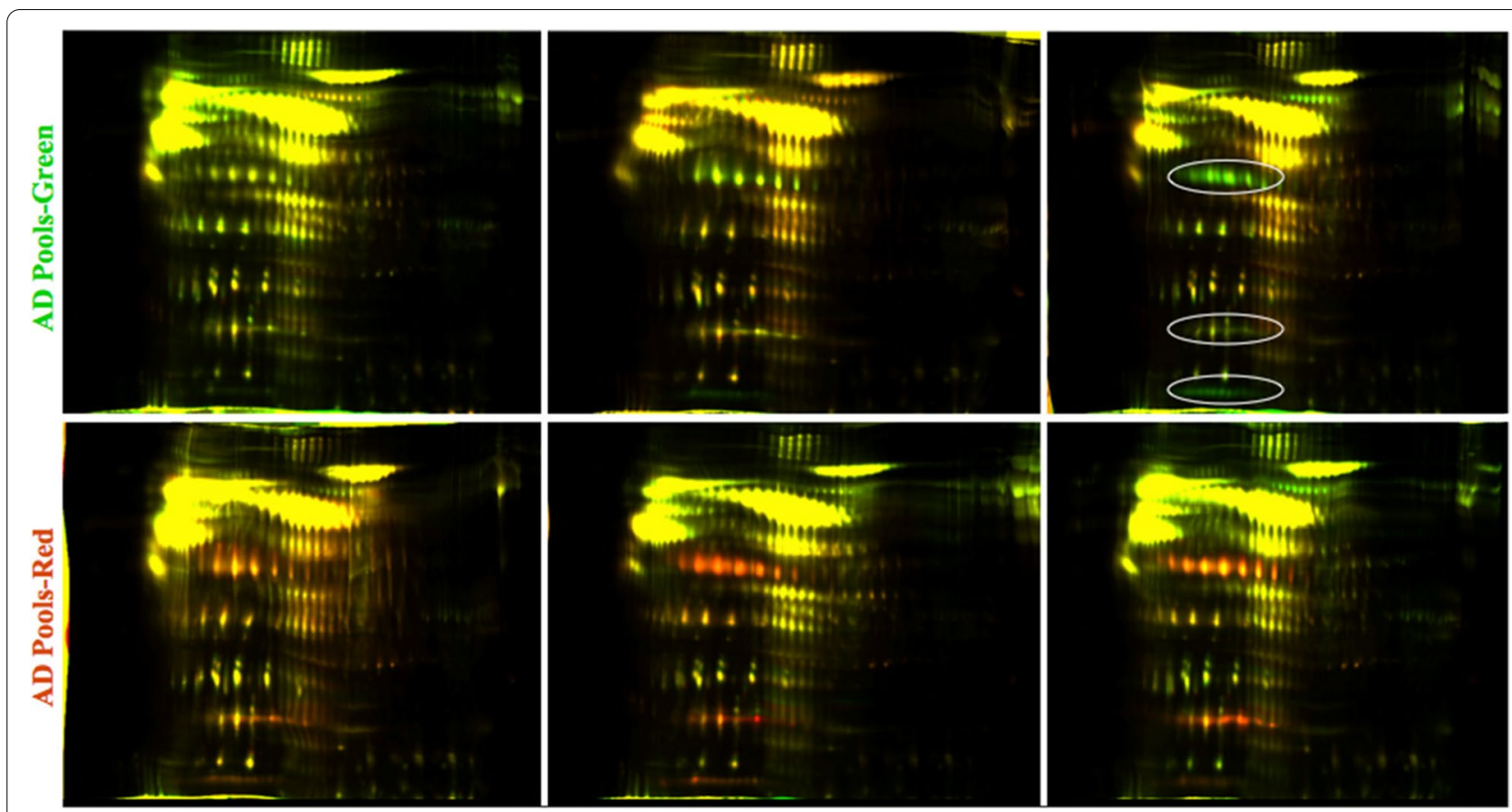

Fig. 3 False-color image overlays of two-color multiplex gels from reverse phase fraction 2 prior to spot-matching alignment. Three subunit chains of $\mathrm{Hpt}$ are outlined in ovals in the upper right image. The AD pools are represented by green in the upper three images and the controls were labeled red. In the lower images the labeling was reversed to control for potential bias induced by the dyes (AD labeled Green and controls labeled Red). Yellow spots represent approximately equal contribution of intensity from AD and control proteins

demonstrated asymmetric sex-dependent AD associations. In female AD pools, several cleavage products of VDBP were in significantly higher concentrations relative to female control pools $(p<0.05)$. In male AD pools, many of the same VDBP cleavage products had significantly lower concentrations, relative to male control pools $(p<0.05$, Fig. 5$)$.

Isoforms of complement factor I (Fig. 2 fraction 3 arrows p, q, r, s) also showed significant asymmetrical sex-specific dysregulation in AD (Table 2).

\section{Targeted validation of 2D gel biomarkers}

The discovery experiment conducted with 2D gels had several limitations, including the use of pooled plasma, which limits the ability to determine the potential for these markers to provide meaningful discriminatory signals in individuals. To validate the differentially expressed proteins in individual samples, we used a multiplexed quantitative LC-MS/MS assay developed by MRM proteomics (BAK76, Canada). Plasma (Li heparin) samples were obtained from AIBL (Demographics Table 3) and included an even number of males and females and cognitively normal controls $(n=44)$ and probable AD $(n=44)$. We could not confirm the elevation of any of the eight proteins we discovered using the pooled samples (Fig. 6). However, we did discover that complement $\mathrm{C} 3$, beta-2-microglobulin and peroxiredoxin-2, proteins, previously reported to be changed in the literature $[28,54-56]$, were elevated in AD plasma

(See figure on next page.)

Fig. 4 A Regression analysis of the basic fraction 5 ApoE variant ( $\varepsilon 4$ proxy) with the fractional APOE $\varepsilon 4$ gene dosage of the 12 pools: $R^{2}=0.83$, $p<0.0001$. Pool symbols are male healthy controls $-X$, female healthy controls $-\Delta$, male $A D-\square$, female $A D-\diamond$. B Regression analysis of total cohort, non-binding a1-antitrypsin (a1AT) variant vs. apoE $\varepsilon 4$ proxy: $R^{2}=0.82, p<0.0001$; Pools are $n=12$. Group symbols are: $A D-\oplus, H C-+$. $C$ Fraction 5 multiplex gels that have not been aligned for spot-matching. Arrows indicate the correlated changes between the $\varepsilon 4$ proxy spot (lower end) and the AD significant a1 AT variant (upper end). The AD pools are represented by red in the upper three images and by green in the lower images, reflecting the dye reversal, used between these gels. Yellow represents approximately equal contribution of intensity from $A D$ and control proteins. D. Detail from a pair of multiplexed gel images representative of low ApoE $\varepsilon 4$ containing pools (panel $i$ ) and high ApoE $\varepsilon 4$ containing pools (panel ii). The level of a1ACT isoforms correlated with the $34 \mathrm{kDa}$ ApoE $\varepsilon 4$ proxy spot that is shown in lower right-hand corners of the panel $i$ and $i i$ images. Regression analysis Pearson correlations: $\mathrm{a}-p=0.012, R^{2}=0.45 ; \mathrm{b}-p=0.002, R^{2}=0.61 ; \mathrm{c}-p=0.003, R^{2}=0.56 ; \mathrm{d}-p=0.002, R^{2}=0.61$; e- $p=0.007, R^{2}=0.51 ; f-p=0.003, R^{2}=0.58$. None of the a ACT spots significantly discriminated the AD group from the HC group. The a 1 AT spot that significantly discriminated AD from HC pools $(3.3$ fold, $p<0.02$ ) is shown in panel ii 


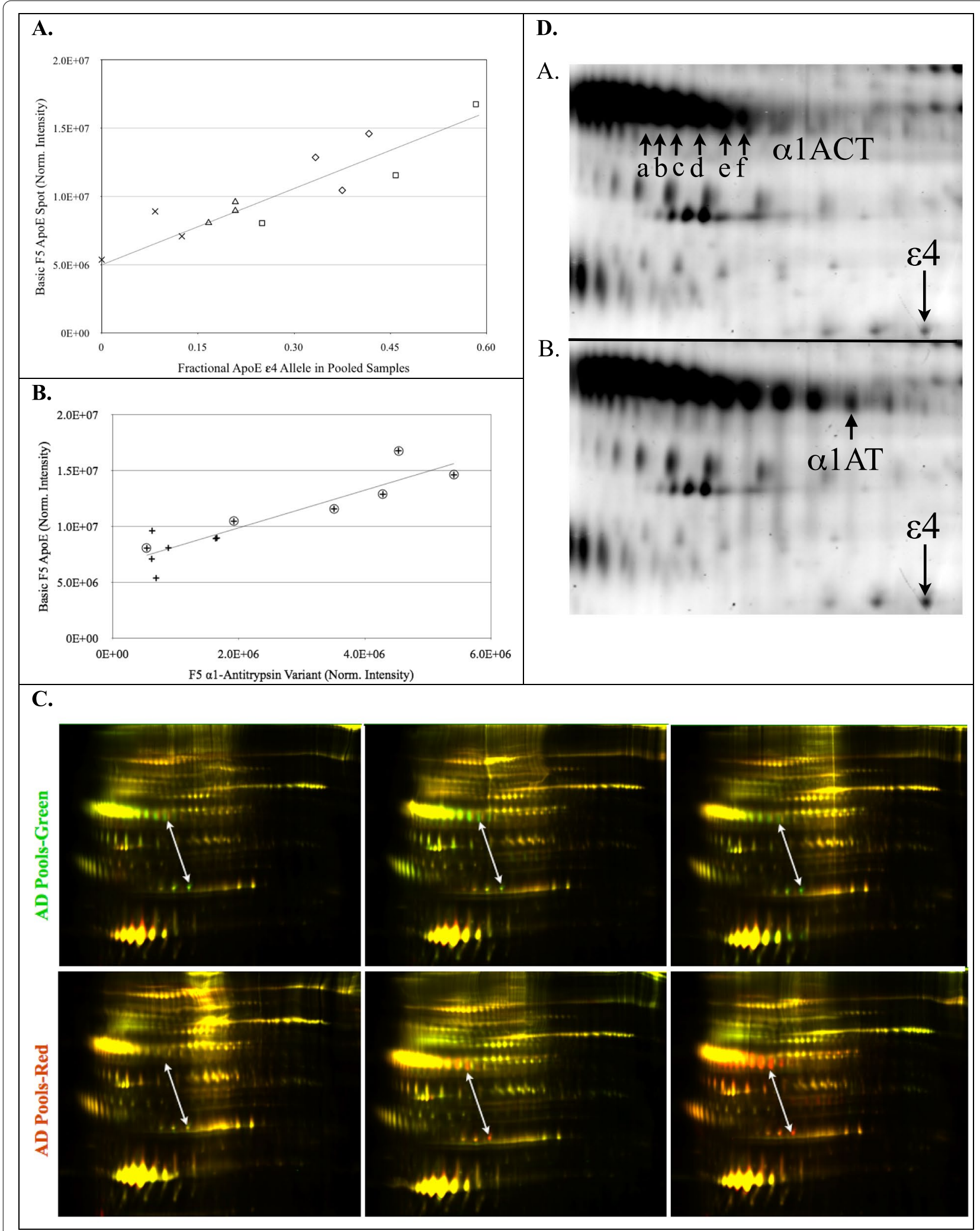

Fig. 4 (See legend on previous page.) 


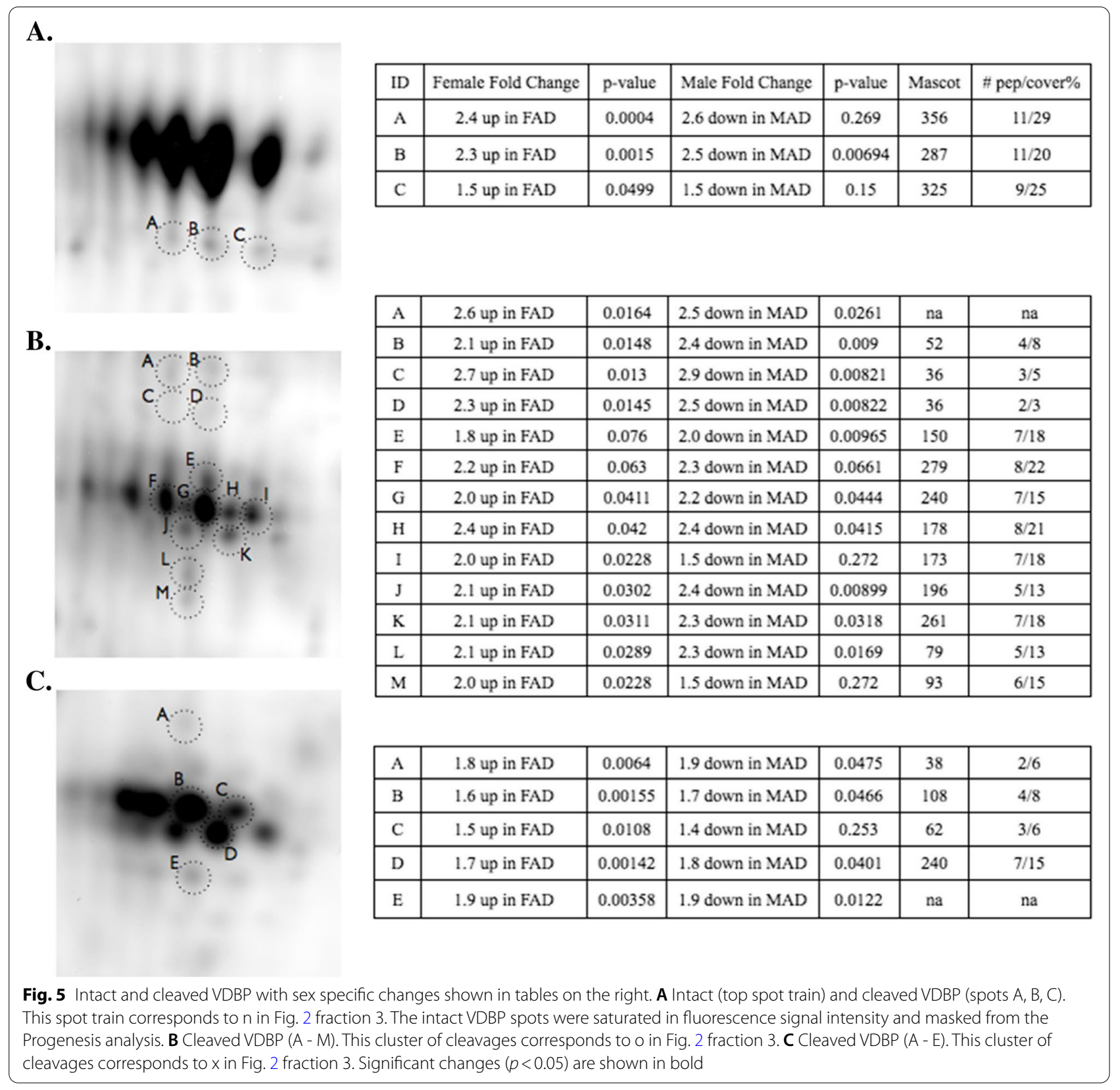

(Fig. 6). We did not replicate any of the associations we observed with sex or genotype in the discovery experiment ( $p>0.05$, one-way ANOVA). However, this likely to be due to the inability to distinguish the several proteoforms that were observed by $2 \mathrm{D}$ gels with an assay that measures total abundance of all the proteoforms of a protein. Receiver operating characteristic (ROC) analysis for complement C3, beta-2-microglobulin and peroxiredoxin 2 indicate that they only have weak discriminatory (accuracy ranged between 60 and 65\%) ability to distinguish between cognitively normal from AD (Table 4).

\section{Discussion}

The effect of the APOE genotype on protein expression is an important consideration for the refinement of discovery and validation of future biomarkers in plasma [57]. Consistent with this we found significant correlation of increasing $\alpha 1$-antitrypsin ( $\alpha 1 \mathrm{AT})$ with APOE $\varepsilon 4$ genotype in plasma. We also found increased levels of cleavage products of VDBP in females with AD and a decrease in the cleavage products in males with $\mathrm{AD}$ (Fig. 5). Due to the enrichment of APOE \&4 genotype in AD cohorts, studies that compare controls vs AD are also confounding 
Table 3 Demographic data for plasma samples used for targeted mass spectrometry biomarker validation

\begin{tabular}{llll}
\hline & Controls & Alzheimer Disease & P-value \\
\hline Age in years & $72.9(6)$ & $76.9(7.4)$ & $0.003^{*}$ \\
\% APOE \&4 & 13 & 37 & $0.01^{\#}$ \\
\% APOE \&2 & 20.5 & 6.8 & $0.06^{\#}$ \\
\% Female & 50 & 50 & \\
Amyloid PET SUVR & $1.17(0.05)$ & $2.35(0.49)^{\mathrm{a}}$ & $2 \mathrm{e}-10$ \\
$\mathrm{n}$ & 44 & 44 & \\
\hline
\end{tabular}

${ }^{*} p$-value calculated using non-paired Student's t-test

$\# p$-value for APOE allele frequency calculated using $N-1 x^{2}$

${ }^{a}$ PET scans are only available for 22 of the 44 cases

populations of $20 \%$ APOE $\varepsilon 4$ positive versus an AD population with $40-80 \%$ APOE $\varepsilon 4$ positive. To the best of our knowledge the current study is the first plasma proteomics study indicating that $\alpha 1 \mathrm{AT}$ or $\alpha 1$ anti-chymotrypsin $(\alpha 1 \mathrm{ACT})$ have correlations with the APOE.

$\alpha-1$ Anti-trypsin ( $\alpha 1 \mathrm{AT})$ is an abundant, circulating, acute phase response (APR) serine protease inhibitor (serpin) that was targeted for removal from the analyte proteins by immuno-depletion (Fig. 1 MARS14). The close correlation of $\alpha 1 \mathrm{AT}$ with the $\varepsilon 4$ proxy variant, shown in Fig. 4B, suggests that $\alpha 1 \mathrm{AT}$ may be a marker of the mode by which APOE $\varepsilon 4$ contributes to the etiology of $\mathrm{AD}$. It is of interest that $\alpha 1 \mathrm{AT}$, which is a serpin with known associations to AD in blood [58-60], CSF [61, 62] and senile plaques [63] also correlated with the APOE $\varepsilon 4$ allele (Fig. 4B), however the specific physiological role of $\alpha 1 \mathrm{AT}$ in tissues is not well elucidated. The Alzgene website shows a single positive genetic association of $\mathrm{AD}$ with an $\alpha 1$ AT allele, from a small, unconfirmed 1996 study [64]. Analysis of total $\alpha 1 \mathrm{AT}$ in neat undepleted plasma from individuals did not display any significant changes (Fig. 6).

The APR serpin, $\alpha 1 \mathrm{ACT}$, did not significantly discriminate $\mathrm{AD}$ from control pools, however, regression analysis of $\alpha 1 \mathrm{ACT}$ variants significantly correlated with the $\varepsilon 4$ proxy spot volumes (Fig. 4D). $\alpha 1 \mathrm{ACT}$ has been reported to have genetic associations with $\mathrm{AD}[65,66]$ and has been found in elevated concentration in plasma $[67,68]$ and CSF [69] in AD. $\alpha 1 \mathrm{ACT}$ is more highly expressed in the brains of $\mathrm{AD}$ patients and is a component of senile plaques [70], as is ApoE [71]. Previous studies have suggested relationships between plasma concentrations of $\alpha 1 \mathrm{ACT}$ and APOE genotype, but the results have been inconsistent. A radial immunodiffusion study found no correlation of APOE genotype with levels of $\alpha 1 \mathrm{ACT}$ in plasma or serum [72]. An enzyme linked immuno-sorption assay study, showed $\alpha 1 \mathrm{ACT}$ to have positive predictive value for the rate of cognitive decline in $\varepsilon 4$ carriers, and no age-dependence, in AD patients [73]. A nephelometric assay study showed higher concentrations of plasma $\alpha 1 \mathrm{ACT}$ in $\mathrm{AD}$ patients who were non-APOE $\varepsilon 4$ carriers [74]. We have shown that cerebral spinal fluid levels of both $\alpha 1 \mathrm{ACT}$ and $\alpha 1 \mathrm{AT}$ are elevated in $\mathrm{AD}$ [75]. Functionally, $\alpha 1 \mathrm{ACT}$ was shown to induce hippocampus and cerebral cortex plaque formation in mouse models of $\mathrm{AD}$ [76], as well as the phosphorylation of tau in the neurons of transgenic mice [77]. Both $\alpha 1 \mathrm{ACT}$ and $\alpha 1 \mathrm{AT}$ bind $A \beta$ and suppress it's fibrillization, which is a necessary process for the formation of senile plaques in vivo [78]. Thus, their role in AD may be more important at the functional level then as a marker of disease.

The elevated Hpt that we observed along with other circulating APR proteins may be a peripheral response to activated endothelia of the brain vessels. Various means by which cross-talk between central and peripheral inflammation may occur have been summarized [79]. The possibility that Hpt flow-through from the immunodepletion column enriched a sub-population of nonbinding conformers may be supported by the selective enrichment of $45 \mathrm{kDa}$ and $8.9 \mathrm{kDa}$ chains in the significantly changed species of AD pools, without a significant change of the $16 \mathrm{kDa}$ chain. The question of whether Hpt was significantly higher in the flow-through because it exceeded the binding capacity of the column, or because of steric hindrance was beyond the scope of this study. In agreement with our observations, a previous report using a MARS column also observed an increase in Hpt in both $\mathrm{AD}$ and type 2 diabetes plasma [80] indicating that an Hpt increase is likely due to a general increase in inflammation. When measured in individuals there was no significant increase (Fig. 6, $p=0.19$ ) in Hpt but this may be due to the inability of the LC-MS/MS method used to discriminate between the 45,16 and $8.9 \mathrm{kDa}$ chains. However, in cerebral spinal fluid we have shown that total levels of Hpt increase in $\mathrm{AD}$ using the same quantitative mass spectrometry technique [75]. Our observation of no change in Hpt in plasma but changes in CSF are consistent with previous reports [81].

Systemic inflammation is commonly measured clinically by assay of plasma C-reactive protein (CRP) [82]. Circulating CRP is primarily synthesized in the liver and, like Hpt, CRP synthesis is mediated by the pro-inflammatory cytokines IL- $1 \beta$ and IL-6 [83]. CRP is elevated in AD brain [84], but is not consistently higher in AD plasma. In the current study, CRP was detected in the 2DGE but when measured in the validation cohort by LC-MS the CRP levels were sporadic and no significant elevation was observed in $\mathrm{AD}$ (Fig. 6). The highly variable nature of the CRP levels is consistent with its role in acute phase inflammation response that changes with a large range of pathologies and not specific for AD. 

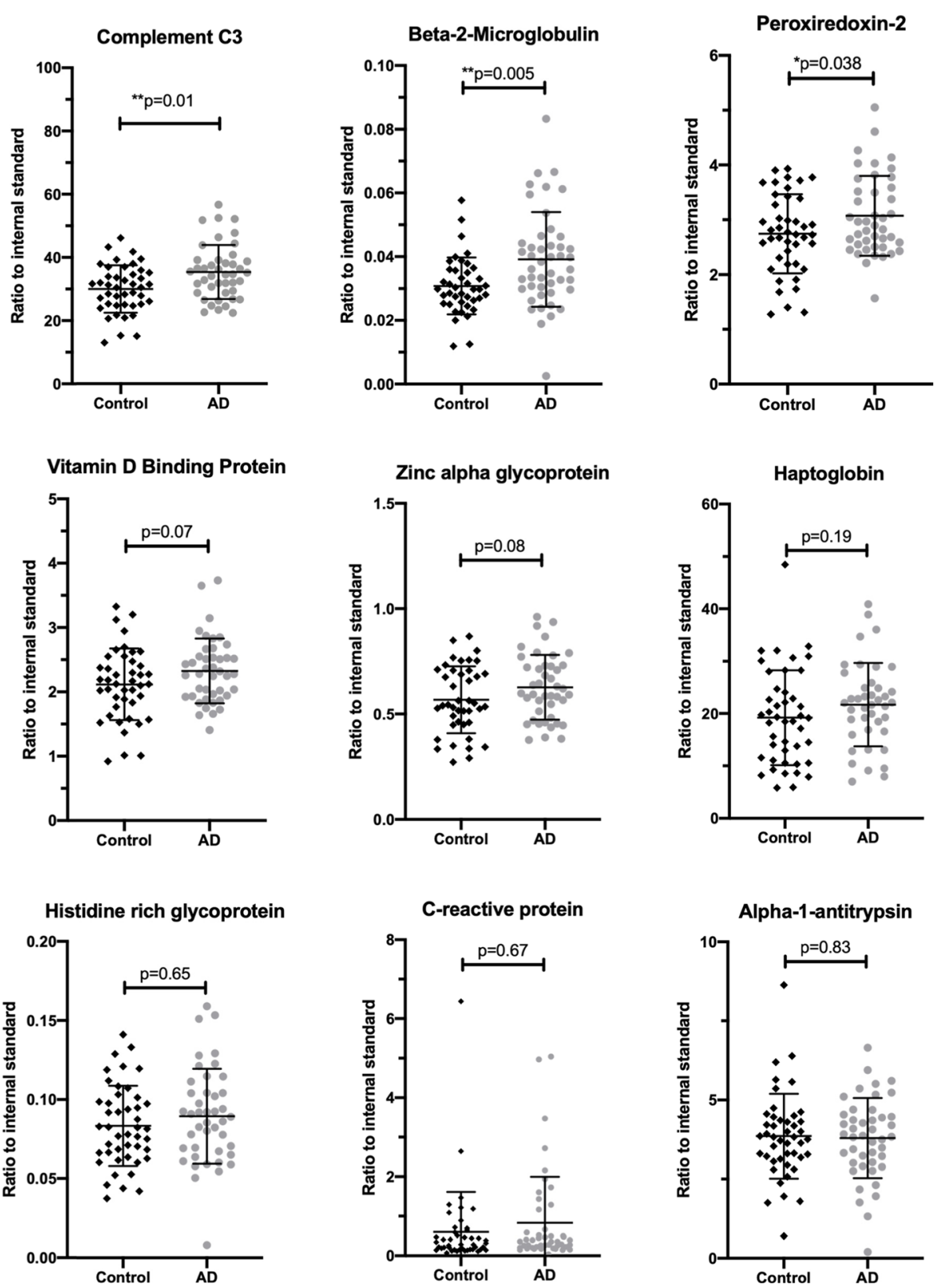

Fig. 6 Measurement of plasma biomarkers in control ( $n=44$, black diamonds) and Alzheimer's disease ( $n=44$, grey circles) plasma. Biomarker candidates discovered using $2 \mathrm{D}$ gels were targeted and measured using LC-MS/MS and heavy labeled $\left(\left[{ }^{13} \mathrm{C}_{6},{ }^{15} \mathrm{~N}_{2}-\right.\right.$-lysine $]$ or $\left[{ }^{13} \mathrm{C}_{6},{ }^{15} \mathrm{~N}_{4}\right.$-arginine) peptides as internal standards. P-values were calculated using a one-way ANOVA and Sidak correction for multiple comparisons [53]

Table 4 Receiver operating characteristic (ROC) analysis of proteins measured by targeted LC-MS assay showing ability to distinguish controls $(n=44)$ from Alzheimer's case $(n=44)$

\begin{tabular}{lllll}
\hline Protein ID & AUC & Sensitivity \% & Specificity \% & $\boldsymbol{P}$-value \\
\hline Complement C3 & 0.65 & 70 & 59 & 0.014 \\
Beta-2-Microglobulin & 0.64 & 42 & 80 & 0.022 \\
Peroxiredoxin-2 & 0.60 & 44 & 72 & 0.098 \\
\hline
\end{tabular}

Zinc a 2-glycoprotein (ZAG) is a $41 \mathrm{kDa}$ glycoprotein adipokine believed to function as a lipid mobilizing factor [85]. In a study with a relatively wide range of body mass indices (BMI), serum ZAG discriminated groups with a negative correlation between BMI and ZAG concentrations [86]. ZAG has been found significantly lower in ventricular CSF of AD patients, discriminating AD from normal 
controls and non-AD dementias [87]. Lower BMI has been associated with risk of $\mathrm{AD}$ [88]. In the current study, BMI data were available for $54 / 72 \mathrm{AD}$ subjects and 60/72 control subjects and was significantly higher in the AD pools (Table 1), consistent with elevated ZAG variants observed. The validation study on individual samples showed a trend $(p=0.06)$ towards elevated levels of ZAG in plasma from AD cases (Fig. 6).

In addition to disease classification, participants were evenly pooled according to sex. A consensus has yet to be reached as to the prevalence of sex-specific differences in $\operatorname{AD}[89,90]$ and there is limited proteomic data on plasma investigating sex specific differences between AD and controls. To look for sex-specific dysregulation of proteins, we made intra-sex comparisons between $\mathrm{AD}$ and $\mathrm{HC}$ pools and found Vitamin D binding protein (VDBP) and Complement factor I (CFI) to be differentially regulated according to sex. VDBP is an abundant, monomeric $52-59 \mathrm{kDa}$ glycoprotein that functions as the primary plasma transporter of the sterol vitamin $\mathrm{D}$ and its metabolites [91]. In addition to its role as vitamin D transporter, VDBP scavenges and sequesters actin monomers in the blood after cellular damage. It does so in concert with gelsolin [92], protecting micro-vasculature from the detrimental effects of ectopic actin fibrillization. VDBP is a regulator of macrophages and osteoclasts, and as an important chemotactic factor for leukocytes [93], independent of its vitamin D binding function. VDBP synthesis is estrogen dependent [94] and its blood concentration is significantly lower in males than females [95, 96]. The gel image of fraction 3 shows three abundant spot-trains of cleaved VDBP species (Fig. 1 fraction 3, arrows $\mathrm{n}, \mathrm{o}, \mathrm{x}$ ), below the intact VDBP spot-train (Fig. 1 fraction 3, arrow $\mathrm{m}$ ). The three spot-train clusters of cleaved peptides focused as disulfide bound complexes in the IEF step, to similar pIs as the uncleaved variants, as they were cross-linked by intra-chain disulfide bridges. After isoelectric focusing, chemical reduction released cleaved peptides to migrate to their respective lower apparent molecular weights. The proteoform difference observed with 2D-gels was not recapitulated with the LC-MS/MS assay that measured the total pool of VDBP (Fig. 6).

CFI is a complement activation inhibitor that has been shown to undergo disrupted function in vitro in the presence of $A \beta$ [97]. CFI plasma concentration is modestly decreased in AD and correlated with brain volume [28], but we found no reports of gender specificity. Further, when measured in individuals we did not see any gender differences.

\section{Conclusion}

The etiology of $\mathrm{AD}$, as for many diseases, is complex and polygenic. Pooled proteomics studies are designed to detect sporadically changing disease-related isoforms that change consistently enough in afflicted subjects to effect consistent "average" changes within pools, and as such constitutes a limitation of the current study. Our future studies aim to validate and understand the relationships between VDBP, CFI, $\alpha 1 \mathrm{ACT}$, and $\alpha 1 \mathrm{AT}$ with sex and genotype, respectively. Here we measured the biomarkers discovered with 2DGE using a quantitative LC-MS/MS assay and the changes we observed by 2DGE were not validated with this approach. However, we did measure samples by quantitative LC-MS/MS that were independent of the discovery study and differences between $\mathrm{AD}$ and control values of several of the markers approached statistical significance (e.g. VDBP; Fig. 6). Overall, the measurement of total protein by LC-MS rather than proteoform-specific changes measured via 2DGE offers a potential explanation for the failure to validate the 2DGE discoveries. However, the replication of elevation of beta-2-microglobulin, complement C3 and peroxiredoxin 2 validate previous reports of these changes in $\mathrm{AD}$ and of the LC-MS/MS based assay to report global protein level changes [28, 54-56]. The correlation $\alpha 1 \mathrm{AT}$ or $\alpha 1 \mathrm{ACT}$ with the $A P O E$ genotype indicates that the point mutation differences between APOE $\varepsilon 2 / 3 / 4$ may have wider impact than on the function of just the ApoE protein as a recent proteomic study in $A D$ brain tissue has demonstrated [57]. Further, the failure to validate many of the proteoform changes highlights the inability of assays that measure the total abundance of a protein target (e.g. ELISA, LC-MS/MS) to reflect the complexity of the proteome. Overall, complement C3, beta-2-microglobulin and peroxiredoxin-2 may add value to the emerging plasma amyloid beta and tau/phosphortau assays for the early diagnosis of AD.

\begin{abstract}
Abbreviations
a1AT: a1-Anti-trypsin; a1ACT: a1 Anti-chymotrypsin; APR: Acute-phase reactant; AD: Alzheimer's disease; APP: Amyloid precursor protein; A $\beta$ : Amyloid $\beta$ peptide; ApoE: Apolipoprotein E protein; BBB: Blood-brain barrier; BMI: Body mass index; CRP: C-reactive protein; CNS: Central Nervous System; CSF: Cerebrospinal fluid; Hpt: Haptoglobin; HC: Healthy control; HRG: Histidinerich glycoprotein; ITIH: Inter-a trypsin inhibitor; Isoelectric point pl: Isoelectric focusing IEF; KPI: Kunitz-type protease inhibitor; RP-HPLC: Reverse phase high pressure liquid chromatography; VDBP: Vitamin D binding protein; ZAG: Zinc a 2-glycoprotein.
\end{abstract}

\section{Supplementary Information}

The online version contains supplementary material available at https://doi. org/10.1186/s12953-021-00185-9.

Additional file 1 


\section{Acknowledgments}

We would like to acknowledge the Australian Imaging and Biomarker, Lifestyle (AIBL) research team (a complete list of researchers can be found at www.aibl. csiro.au) and the volunteers and their families. We would also like to acknowledge funding from the Dementia Collaborative Research Centres (DCRC), The Victorian Government's Operational Infrastructure Support Program and the Wicking Trust. National Institutes of Health- Small Business Technology Transfer (NIH STTR grant 5R42RR021790, EAD PI), Center for Biological Research Excellence (NIH CoBRE grants 1P20RR024237 and 2P20GM 104935 , EAD PI), Montana Board of Research and Commercialization Technology Grants: (MBRCT: 05-14, 06-46, and 08-17, EAD PI) and the Murdock Charitable Trust (EAD, PI). The Cooperative Research Centre for Mental Health, Alzheimer's Drug Discovery Foundation grant (BRR, PI), Knott Family Equipment Grant (BRR, PI), the Pierce Armstrong Trust (BRR, PI), NHMRC Dementia Leadership Fellowship (BR, APP1138673), and NHMRC project grant (BR, APP1164692). The Florey Neuroproteomics Facility. We would like to thank the Melbourne Mass Spectrometry and Proteomics Facility of The Bio21 Molecular Science and Biotechnology Institute at The University of Melbourne for the support of mass spectrometry analysis.

\section{Authors' contributions}

B.R.R., S.B.L. and E.A.D designed the research. S.B.L., B.R.R., A.M.R., J.A.V., B.D.R, K.K.P., R.L.R, C.J.F, and B.T. performed the experiments. P.A.G. and E.A.D. designed Zdye reagents. D.A., A.I.B., R.M., C.L.M. collection of clinical samples. S.B.L., B.R.R., A.M.R. and J.D.D. analyzed the data. S.B.L., E.A.D. and B.R.R. wrote the manuscript. All authors were involved in editing and critically revising the manuscript; and have read and approved the final version.

\section{Funding}

National Institutes of Health

(5R42RR021790)

Dr. Edward A Dratz

National Institutes of Health

(1P20RR024237)

Dr. Edward A Dratz

National Health and Medical Research Council

(1164692)

Dr. Blaine R Roberts

National Health and Medical Research Council

(1138673)

Dr. Blaine R Roberts

Alzheimer's Drug Discovery Foundation Dr. Blaine R Roberts

\section{Availability of data and materials}

The proteomics data used to support the findings of this study are available from the corresponding author upon request.

\section{Declarations}

\section{Ethics approval and consent to participate}

Ethical approval for this study was provided by The University of Melbourne Human Research Ethics Committee. Prior written informed consent was obtained from all participants.

\section{Consent for publication}

All authors consent that the details and images will be freely available on the internet. None of the authors are government employees. All authors consent to the manuscript, text, and pictures being published by Proteome Science and used for commercial purposes. All authors have read and approved of the manuscript.

\section{Competing interests}

EAD and PAG are founders and shareholders in Zdye LLC, which licenses patents issued to Montana State University and reagents used in the present study. BRR, SBL and EAD are inventors on PCT application AU2014/000849. BRR receives research support from Agilent Technologies and from eMSion Inc. (OR, USA). All other authors declare that no competing interests exist.

\section{Author details}

${ }^{1}$ Florey Institute of Neuroscience and Mental Health and The University of Melbourne Dementia Research Centre, Parkville, VIC 3010, Australia. ${ }^{2}$ Department of Chemistry and Biochemistry, Montana State University, Bozeman, MT 59715, USA. ${ }^{3}$ Cooperative Research Centre for Mental Health, Carlton South, VIC, Australia. ${ }^{4}$ Australian e-Health Research Centre, CSIRO and Cooperative Research Centre of Mental Health, Royal Brisbane and Women's Hospital, Brisbane, QLD 4029, Australia. ${ }^{5}$ Department of Biochemistry, Emory School of Medicine, 4001 Rollins Research Building, Atlanta, GA 30322, USA. ' Department of Neurology, Emory School of Medicine, 4001 Rollins Research Building, Atlanta, GA 30322, USA. ${ }^{7}$ AIT Bioscience, 7840 Innovation Blvd., Indianapolis, IN 46278, USA.

${ }^{8}$ School of Medical Sciences, Edith Cowan University, Joondalup, WA, Australia.

${ }^{9}$ Department of Biomedical Sciences, Macquarie University, North Ryde, NSW, Australia.

Received: 13 September 2021 Accepted: 23 December 2021

Published online: 26 January 2022

\section{References}

1. Alzheimer's, A. 2014 Alzheimer's disease facts and figures. Alzheimers Dement. 2014:10:e47-92.

2. Barnett $J H$, Lewis L, Blackwell AD, Taylor M. Early intervention in Alzheime's disease: a health economic study of the effects of diagnostic timing. BMC Neurol. 2014;14:101.

3. Breteler MM. Early life circumstances and late life Alzheimer's disease. Epidemiology. 2001;12:378-9.

4. Jellinger KA, Janetzky B, Attems J, Kienzl E. Biomarkers for early diagnosis of Alzheimer disease: 'ALZheimer ASsociated gene'--a new blood biomarker? J Cell Mol Med. 2008;12:1094-117.

5. Villemagne VL, Burnham S, Bourgeat P, Brown B, Ellis KA, Salvado O, et al. Amyloid beta deposition, neurodegeneration, and cognitive decline in sporadic Alzheimer's disease: a prospective cohort study. Lancet Neurol. 2013;12:357-67.

6. Blennow K, Dubois B, Fagan AM, Lewczuk P, de Leon MJ, Hampel H. Clinical utility of cerebrospinal fluid biomarkers in the diagnosis of early Alzheimer's disease. Alzheimers Dement. 2015;11:58-69.

7. Holtzman DM. CSF biomarkers for Alzheimer's disease: current utility and potential future use. Neurobiol Aging. 2011;32(Suppl 1):S4-9.

8. Starr JM, Farrall AJ, Armitage P, McGurn B, Wardlaw J. Blood-brain barrier permeability in Alzheimer's disease: a case-control MRI study. Psychiatry Res. 2009;171:232-41.

9. Zipser BD, Johanson CE, Gonzalez L, Berzin TM, Tavares R, Hulette CM, et al. Microvascular injury and blood-brain barrier leakage in Alzheimer's disease. Neurobiol Aging. 2007;28:977-86.

10. Banks WA. Brain meets body: the blood-brain barrier as an endocrine interface. Endocrinology. 2012;153:4111-9.

11. Hartai Z, Juhász A, Rimanóczy Á, Janáky T, Donkó T, Dux L, et al. Decreased serum and red blood cell kynurenic acid levels in Alzheimer's disease. Neurochem Int. 2007:50:308-13.

12. Mohanty JG, Shukla HD, Williamson JD, Launer LJ, Saxena S, Rifkind JM. Alterations in the red blood cell membrane proteome in Alzheimer's subjects reflect disease-related changes and provide insight into altered cell morphology. Proteome Sci. 2010;8:11.

13. Faux NG, Rembach A, Wiley J, Ellis KA, Ames D, Fowler CJ, et al. An anemia of Alzheimer's disease. Mol Psychiatry. 2014;19:1227-34.

14. Ryan TM, Roberts BR, McColl G, Hare DJ, Doble PA, Li QX, et al. Stabilization of nontoxic Abeta-oligomers: insights into the mechanism of action of hydroxyquinolines in Alzheimer's disease. J Neurosci. 2015;35:2871-84.

15. Fu T-K, Matsuyama SS, Kessler JO, Jarvik LF. Philothermal response, microtubules and dementia. Neurobiol Aging. 1986;7:41-3.

16. Jarvik LF, Matsuyama SS, Kessler JO, Fu TK, Tsau S, Clark EO. Philothermal response of polymorphonuclear leukocytes in dementia of the Alzheimer type. Neurobiol Aging. 1982;3:93-9.

17. Scott RB, Collins JM, Hunt PA. Alzheimer's disease and Down syndrome: leukocyte membrane fluidity alterations. Mech Ageing Dev. 1994;75:1-10.

18. Burnham SC, Faux NG, Wilson W, Laws SM, Ames D, Bedo J, et al. A bloodbased predictor for neocortical Abeta burden in Alzheimer's disease: results from the AIBL study. Mol Psychiatry. 2014;19:519-26.

19. Doecke JD, Laws SM, Faux NG, Wilson W, Burnham SC, Lam CP, et al. Blood-based protein biomarkers for diagnosis of Alzheimer disease. Arch Neurol. 2012;69:1318-25. 
20. Guo LH, Alexopoulos P, Wagenpfeil S, Kurz A, Perneczky R, Alzheimer's Disease Neuroimaging, I. Plasma proteomics for the identification of Alzheimer disease. Alzheimer Dis Assoc Disord. 2013;27:337-42.

21. Hye A, Lynham S, Thambisetty M, Causevic M, Campbell J, Byers HL, et al. Proteome-based plasma biomarkers for Alzheimer's disease. Brain. 2006;129(11):3042-50.

22. Llano DA, Devanarayan V, Simon AJ, Alzheimer's Disease Neuroimaging, I. Evaluation of plasma proteomic data for Alzheimer disease state classification and for the prediction of progression from mild cognitive impairment to Alzheimer disease. Alzheimer Dis Assoc Disord. 2013;27:233-43.

23. Song F, Poljak A, Kochan NA, Raftery M, Brodaty H, Smythe GA, Sachdev PS. Plasma protein profiling of Mild Cognitive Impairment and Alzheimer's disease using iTRAQ quantitative proteomics. Proteome Sci. 2014;12(1):5. https://doi.org/10.1186/1477-5956-12-5.

24. Muenchhoff J, Poljak A, Song F, Raftery M, Brodaty H, Duncan M, et al. Plasma protein profiling of mild cognitive impairment and Alzheimer's disease across two independent cohorts. J Alzheimers Dis. 2015:43:1355-73.

25. Lonneborg A. Biomarkers for Alzheimer disease in cerebrospinal fluid, urine, and blood. Mol Diagn Ther. 2008;12:307-20.

26. Snyder HM, Corriveau RA, Craft S, Faber JE, Greenberg SM, Knopman D, Lamb BT, Montine TJ, Nedergaard M, Schaffer CB, Schneider JA, Wellington C, Wilcock DM, Zipfel GJ, Zlokovic B, Bain LJ, Bosetti F, Galis ZS, Koroshetz W, Carrillo MC. Vascular contributions to cognitive impairment and dementia including Alzheimer's disease. Alzheimers Dement. 2015;1 16):710-7. https://doi.org/10.1016/j.jalz.2014.10.008. Epub 2014 Dec 12.

27. Teunissen CE, de Vente J, Steinbusch HW, De Bruijn C. Biochemical markers related to Alzheimer's dementia in serum and cerebrospinal fluid. Neurobiol Aging. 2002;23:485-508.

28. Thambisetty M, Simmons A, Hye A, Campbell J, Westman E, Zhang Y, et al. Plasma biomarkers of brain atrophy in Alzheimer's disease. PLoS One. 2011;6:e28527.

29. Chen Z, Mengel D, Keshavan A, Rissman RA, Billinton A, Perkinton M, et al. Learnings about the complexity of extracellular tau aid development of a blood-based screen for Alzheimer's disease. Alzheimers Dement. 2019:15:487-96

30. Lue LF, Sabbagh MN, Chiu MJ, Jing N, Snyder NL, Schmitz C, et al. Plasma levels of Abeta42 and tau identified probable Alzheimer's dementia: findings in two cohorts. Front Aging Neurosci. 2017;9:226.

31. Nakamura A, Kaneko N, Villemagne VL, Kato T, Doecke J, Dore V, et al. High performance plasma amyloid-beta biomarkers for Alzheimer's disease. Nature. 2018;554:249-54.

32. Risacher SL, Fandos N, Romero J, Sherriff I, Pesini P, Saykin AJ, et al. Plasma amyloid beta levels are associated with cerebral amyloid and tau deposition. Alzheimers Dement (Amst). 2019;11:510-9.

33. Schindler SE, Bollinger JG, Ovod V, Mawuenyega KG, Li Y, Gordon BA, et al. High-precision plasma beta-amyloid $42 / 40$ predicts current and future brain amyloidosis. Neurology. 2019;93:e1647-59.

34. Palmqvist S, Janelidze S, Quiroz YT, Zetterberg H, Lopera F, Stomrud E, et al. Discriminative accuracy of plasma Phospho-tau217 for Alzheimer disease vs other neurodegenerative disorders. JAMA. 2020;324:772-81.

35. Abdi F, Quinn JF, Jankovic J, McIntosh M, Leverenz JB, Peskind E, et al. Detection of biomarkers with a multiplex quantitative proteomic platform in cerebrospinal fluid of patients with neurodegenerative disorders. J Alzheimers Dis. 2006;9:293-348.

36. Anderson NL, Anderson NG. The human plasma proteome: history, character, and diagnostic prospects. Mol Cell Proteomics. 2002;1:845-67.

37. Jacobs JM, Adkins JN, Qian WJ, Liu T, Shen Y, Camp DG 2nd, et al. Utilizing human blood plasma for proteomic biomarker discovery. J Proteome Res. 2005:4:1073-85.

38. Zolotarjova N, Mrozinski P, Chen H, Martosella J. Combination of affinity depletion of abundant proteins and reversed-phase fractionation in proteomic analysis of human plasma/serum. J Chromatogr A. 2008; 1189:332-8.

39. Diz AP, Truebano M, Skibinski DO. The consequences of sample pooling in proteomics: an empirical study. Electrophoresis. 2009;30:2967-75.

40. Oberg AL, Vitek O. Statistical design of quantitative mass spectrometrybased proteomic experiments. J Proteome Res. 2009;8:2144-56.
41. Dratz EA, Grieco PA. (2010) Novel zwitterionic dyes for labeling in proteomic and other biological analyses. US20200036133A1 U.S. Patent and Trademark Office. https://uspto.report/patent/app/20040248203.

42. Epstein MG, Reeves BD, Maaty WS, Fouchard D, Dratz EA, Bothner B, et al. Enhanced sensitivity employing zwitterionic and pl balancing dyes (Z-CyDyes) optimized for 2D-gel electrophoresis based on side chain modifications of CyDye fluorophores. New tools for use in proteomics and diagnostics. Bioconjug Chem. 2013;24:1552-61.

43. Ellis KA, Bush Al, Darby D, De Fazio D, Foster J, Hudson P, et al. The Australian Imaging, Biomarkers and Lifestyle (AIBL) study of aging: methodology and baseline characteristics of 1112 individuals recruited for a longitudinal study of Alzheimer's disease. Int Psychogeriatr. 2009;21:672-87.

44. McKhann GM, Knopman DS, Chertkow H, Hyman BT, Jack CR Jr, Kawas $\mathrm{CH}$, et al. The diagnosis of dementia due to Alzheimer's disease: recommendations from the National Institute on Aging-Alzheimer's Association workgroups on diagnostic guidelines for Alzheimer's disease. Alzheimers Dement. 2011;7:263-9.

45. Hixson JE, Vernier DT. Restriction isotyping of human apolipoprotein E by gene amplification and cleavage with Hhal. J Lipid Res. 1990;31 (3):545-8.

46. Storey JD, Tibshirani R. Statistical significance for genomewide studies. Proc Natl Acad Sci U S A. 2003;100:9440-5.

47. Shevchenko A, Tomas H, Havlis J, Olsen JV, Mann M. In-gel digestion for mass spectrometric characterization of proteins and proteomes. Nat Protoc. 2006;1:2856-60.

48. Heffernan AL, Chidgey C, Peng P, Masters CL, Roberts BR. The neurobiology and age-related prevalence of the epsilon4 allele of apolipoprotein $\mathrm{E}$ in Alzheimer's disease cohorts. J Mol Neurosci. 2016;60:316-24.

49. Pike KE, Savage G, Villemagne VL, Ng S, Moss SA, Maruff P, et al. Betaamyloid imaging and memory in non-demented individuals: evidence for preclinical Alzheimer's disease. Brain. 2007;130:2837-44.

50. Langlois MR, Delanghe JR. Biological and clinical significance of haptoglobin polymorphism in humans. Clin Chem. 1996;42:1589-600.

51. Wernette-Hammond ME, Lauer SJ, Corsini A, Walker D, Taylor JM, Rall SC Jr. Glycosylation of human apolipoprotein E. The carbohydrate attachment site is threonine 194. J Biol Chem. 1989:264:9094-101.

52. Sarioglu H, Lottspeich F, Walk T, Jung G, Eckerskorn C. Deamidation as a widespread phenomenon in two-dimensional polyacrylamide gel electrophoresis of human blood plasma proteins. Electrophoresis. 2000;21:2209-18.

53. Abdi H. The Bonferonni and Šidák corrections for multiple comparisons. Thousand Oaks: Sage; 2007.

54. Davidsson P, Westman-Brinkmalm A, Nilsson CL, Lindbjer M, Paulson L, Andreasen $\mathrm{N}$, et al. Proteome analysis of cerebrospinal fluid proteins in Alzheimer patients. Neuroreport. 2002;13:611-5.

55. Dominici R, Finazzi D, Polito L, Oldoni E, Bugari G, Montanelli A, et al. Comparison of beta2-microglobulin serum level between Alzheimer's patients, cognitive healthy and mild cognitive impaired individuals. Biomarkers. 2018;23:603-8.

56. Yoshida Y, Yoshikawa A, Kinumi T, Ogawa Y, Saito Y, Ohara K, et al. Hydroxyoctadecadienoic acid and oxidatively modified peroxiredoxins in the blood of Alzheimer's disease patients and their potential as biomarkers. Neurobiol Aging. 2009;30:174-85.

57. Dai J, Johnson ECB, Dammer EB, Duong DM, Gearing M, Lah JJ, et al. Effects of APOE genotype on brain proteomic network and cell type changes in Alzheimer's disease. Front Mol Neurosci. 2018;1 1:454.

58. Choi J, Malakowsky CA, Talent JM, Conrad CC, Gracy RW. Identification of oxidized plasma proteins in Alzheimer's disease. Biochem Biophys Res Commun. 2002:293:1566-70.

59. Liao PC, Yu L, Kuo CC, Lin C, Kuo YM. Proteomics analysis of plasma for potential biomarkers in the diagnosis of Alzheimer's disease. Proteomics Clin Appl. 2007;1:506-12.

60. Yu HL, Chertkow HM, Bergman H, Schipper HM. Aberrant profiles of native and oxidized glycoproteins in Alzheimer plasma. Proteomics. 2003:3:2240-8.

61. Finehout EJ, Franck Z, Choe LH, Relkin N, Lee KH. Cerebrospinal fluid proteomic biomarkers for Alzheimer's disease. Ann Neurol. 2007;61:120-9.

62. Puchades M, Hansson SF, Nilsson CL, Andreasen N, Blennow K, Davidsson P. Proteomic studies of potential cerebrospinal fluid protein markers for Alzheimer's disease. Brain Res Mol Brain Res. 2003;1 18:140-6. 
63. Gollin PA, Kalaria RN, Eikelenboom P, Rozemuller A, Perry G. Alpha 1-antitrypsin and alpha 1-antichymotrypsin are in the lesions of Alzheimer's disease. Neuroreport. 1992;3:201-3.

64. Kowalska A, Danker-Hopfe H, Wender M, Florczak J, Walter H. Association between the $\mathrm{Pl}^{*} \mathrm{M} 3$ allele of a1-antitrypsin and Alzheimer's disease? A preliminary report. Hum Genet. 1996;98:744-6.

65. Licastro F, Pedrini S, Ferri C, Casadei V, Govoni M, Pession A, et al. Gene polymorphism affecting alpha1-antichymotrypsin and interleukin-1 plasma levels increases Alzheimer's disease risk. Ann Neurol. 2000;48:388-91.

66. Licastro F, Pedrini S, Govoni M, Pession A, Ferri C, Annoni G, et al. Apolipoprotein $\mathrm{E}$ and alpha-1-antichymotrypsin allele polymorphism in sporadic and familial Alzheimer's disease. Neurosci Lett. 1999;270:129-32.

67. Engelhart MJ, Geerlings MI, Meijer J, Kiliaan A, Ruitenberg A, van Swieten $\mathrm{JC}$, et al. Inflammatory proteins in plasma and the risk of dementia: the Rotterdam study. Arch Neurol. 2004;61:668-72.

68. Licastro F, Pedrini S, Caputo L, Annoni G, Davis LJ, Ferri C, et al. Increased plasma levels of interleukin-1, interleukin- 6 and alpha-1-antichymotrypsin in patients with Alzheimer's disease: peripheral inflammation or signals from the brain? J Neuroimmunol. 2000;103:97-102.

69. Nielsen H, Minthon L, Londos E, Blennow K, Miranda E, Perez J, et al. Plasma and CSF serpins in Alzheimer disease and dementia with Lewy bodies. Neurology. 2007;69:1569-79.

70. Abraham CR, Selkoe DJ, Potter H. Immunochemical identification of the serine protease inhibitor alpha 1-antichymotrypsin in the brain amyloid deposits of Alzheimer's disease. Cell. 1988;52:487-501.

71. Strittmatter WJ, Saunders AM, Schmechel D, Pericak-Vance M, Enghild J, Salvesen GS, et al. Apolipoprotein E: high-avidity binding to beta-amyloid and increased frequency of type 4 allele in late-onset familial Alzheimer disease. Proc Natl Acad Sci U S A. 1993;90:1977-81.

72. Licastro F, Masliah E, Pedrini S, Thal LJ. Blood levels of alpha-1-antichymotrypsin and risk factors for Alzheimer's disease: effects of gender and apolipoprotein E genotype. Dement Geriatr Cogn Disord. 1999;11:25-8.

73. Porcellini E, Davis EJ, Chiappelli M, Ianni E, Di Stefano G, Forti P, et al. Elevated plasma levels of alpha-1-anti-chymotrypsin in age-related cognitive decline and Alzheimer's disease: a potential therapeutic target. Curr Pharm Des. 2008;14:2659-64

74. Scacchi R, Ruggeri M, Gambina G, Martini MC, Ferrari G, Corbo RM. Plasma alpha1-antichymotrypsin in Alzheimer's disease; relationships with APOE genotypes. Neurobiol Aging. 2001;22:413-6.

75. Ayton S, Janelidze S, Roberts B, Palmqvist S, Kalinowski P, Diouf I, et al. Acute phase markers in CSF reveal inflammatory changes in Alzheimer's disease that intersect with pathology, APOE epsilon4, sex and age. Prog Neurobiol. 2021;198:101904.

76. Nilsson LN, Bales KR, DiCarlo G, Gordon MN, Morgan D, Paul SM, et al. Alpha-1-antichymotrypsin promotes beta-sheet amyloid plaque deposition in a transgenic mouse model of Alzheimer's disease. J Neurosci. 2001;21:1444-51.

77. Padmanabhan J, Levy M, Dickson DW, Potter H. Alpha1-antichymotrypsin, an inflammatory protein overexpressed in Alzheimer's disease brain, induces tau phosphorylation in neurons. Brain. 2006;129:3020-34.

78. Giunta S, Galeazzi R, Marcellini M, Corder E, Galeazzi L. The inflammationsensitive protein alpha 1-anti-chymotrypsin neutralizes fibrillar aggregation and cytotoxicity of the beta-amyloid peptide more effectively than alpha 1-antitrypsin. Clin Biochem. 2007:40:887-92.

79. Holmes C. Review: systemic inflammation and Alzheimer's disease. Neuropathol Appl Neurobiol. 2013;39:51-68.

80. Zhang R, Barker L, Pinchev D, Marshall J, Rasamoelisolo M, Smith C, et al. Mining biomarkers in human sera using proteomic tools. Proteomics. 2004:4:244-56

81. Chang KH, Tseng MY, Ro LS, Lyu RK, Tai YH, Chang HS, et al. Analyses of haptoglobin level in the cerebrospinal fluid and serum of patients with neuromyelitis optica and multiple sclerosis. Clin Chim Acta. 2013:417:26-30.

82. Mortensen RF. C-reactive protein, inflammation, and innate immunity. Immunol Res. 2001;24:163-76.

83. Bode JG, Albrecht U, Haussinger D, Heinrich PC, Schaper F. Hepatic acute phase proteins--regulation by IL-6- and IL-1-type cytokines involving STAT3 and its crosstalk with NF-kappaB-dependent signaling. Eur J Cell Biol. 2012;91:496-505
84. Wood JA, Wood PL, Ryan R, Graff-Radford NR, Pilapil C, Robitaille Y, et al. Cytokine indices in Alzheimer's temporal cortex: no changes in mature IL-1 beta or IL-1RA but increases in the associated acute phase proteins IL-6, alpha 2-macroglobulin and C-reactive protein. Brain Res. 1993:629:245-52

85. Hirai K, Hussey HJ, Barber MD, Price SA, Tisdale MJ. Biological evaluation of a lipid-mobilizing factor isolated from the urine of cancer patients. Cancer Res. 1998;58:2359-65.

86. Selva DM, Lecube A, Hernandez C, Baena JA, Fort JM, Simo R. Lower zinc-alpha2-glycoprotein production by adipose tissue and liver in obese patients unrelated to insulin resistance. J Clin Endocrinol Metab. 2009;94:4499-507.

87. Roher AE, Maarouf CL, Sue LI, Hu Y, Wilson J, Beach TG. Proteomicsderived cerebrospinal fluid markers of autopsy-confirmed Alzheimer's disease. Biomarkers. 2009;14:493-501.

88. Shah RC, Buchman AS, Wilson RS, Leurgans SE, Bennett DA. Hemoglobin level in older persons and incident Alzheimer disease: prospective cohort analysis. Neurology. 2011;77:219-26.

89. Barnes LL, Wilson RS, Bienias JL, Schneider JA, Evans DA, Bennett DA. Sex differences in the clinical manifestations of Alzheimer disease pathology. Arch Gen Psychiatry. 2005;62:685-91.

90. Ruitenberg A, Ott A, van Swieten JC, Hofman A, Breteler MM. Incidence of dementia: does gender make a difference? Neurobiol Aging. 2001:22:575-80.

91. Kawakami M, Blum CB, Ramakrishnan R, Dell RB, Goodman DS. Turnover of the plasma binding protein for vitamin $D$ and its metabolites in normal human subjects. J Clin Endocrinol Metab. 1981;53:1110-6.

92. White $\mathrm{P}$, Cooke $\mathrm{N}$. The multifunctional properties and characteristics of vitamin D-binding protein. Trends Endocrinol Metab. 2000;11:320-7.

93. Disanto G, Ramagopalan SV, Para AE, Handunnetthi L. The emerging role of vitamin D binding protein in multiple sclerosis. J Neurol. 2011;258:353-8.

94. Bouillon R, Van Assche FA, Van Baelen H, Heyns W, De Moor P. Influence of the vitamin D-binding protein on the serum concentration of 1,25-dihydroxyvitamin D3. Significance of the free 1,25-dihydroxyvitamin D3 concentration. J Clin Invest. 1981;67:589-96.

95. Blanton D, Han Z, Bierschenk L, Linga-Reddy MV, Wang H, Clare-Salzler $M$, et al. Reduced serum vitamin D-binding protein levels are associated with type 1 diabetes. Diabetes. 2011;60:2566-70.

96. Bolland MJ, Grey AB, Ames RW, Horne AM, Mason BH, Wattie DJ, et al. Age-, gender-, and weight-related effects on levels of 25-hydroxyvitamin D are not mediated by vitamin D binding protein. Clin Endocrinol. 2007;67:259-64.

97. Wang J, Ohno-Matsui K, Yoshida T, Kojima A, Shimada N, Nakahama K, et al. Altered function of factor I caused by amyloid beta: implication for pathogenesis of age-related macular degeneration from Drusen. J Immunol. 2008;181:712-20.

\section{Publisher's Note}

Springer Nature remains neutral with regard to jurisdictional claims in published maps and institutional affiliations. 